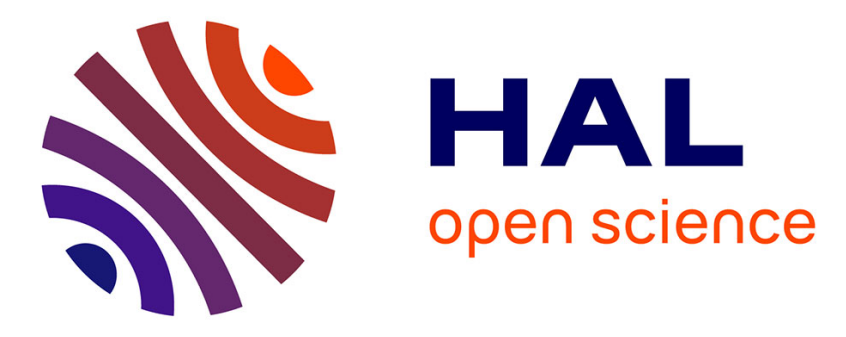

\title{
Web Accessibility for Visually Impaired People: Requirements and Design Issues
}

\author{
Mexhid Ferati, Bahtijar Vogel, Arianit Kurti, Bujar Raufi, David Salvador
}

Astals

\section{- To cite this version:}

Mexhid Ferati, Bahtijar Vogel, Arianit Kurti, Bujar Raufi, David Salvador Astals. Web Accessibility for Visually Impaired People: Requirements and Design Issues. 1st and 2nd International Workshop on Usability- and Accessibility-Focused Requirements Engineering (UsARE 2012 / UsARE 2014), Jun 2012, Zurich, Switzerland. pp.79-96, 10.1007/978-3-319-45916-5_6 . hal-01631308

\section{HAL Id: hal-01631308 https://hal.inria.fr/hal-01631308}

Submitted on 9 Nov 2017

HAL is a multi-disciplinary open access archive for the deposit and dissemination of scientific research documents, whether they are published or not. The documents may come from teaching and research institutions in France or abroad, or from public or private research centers.
L'archive ouverte pluridisciplinaire HAL, est destinée au dépôt et à la diffusion de documents scientifiques de niveau recherche, publiés ou non, émanant des établissements d'enseignement et de recherche français ou étrangers, des laboratoires publics ou privés.

\section{(c)(1)}

Distributed under a Creative Commons Attribution| 4.0 International License 


\title{
Web Accessibility for Visually Impaired People: Requirements and Design Issues
}

\author{
Mexhid Ferati ${ }^{1}$, Bahtijar Vogel ${ }^{2}$, Arianit Kurti ${ }^{3,4}$, Bujar Raufi ${ }^{5}$, David Salvador \\ Astals $^{6}$ \\ ${ }^{1}$ Oslo and Akershus University College of Applied Sciences, Oslo, Norway \\ mexhid.ferati@hioa.no \\ ${ }^{2}$ Malmö University, Malmö, Sweden \\ bahtijar.vogel@mah.se \\ ${ }^{3}$ Linnaeus University, Växjö, Sweden \\ arianit.kurti@lnu.se \\ ${ }^{4}$ Interactive Institute Swedish ICT, Norrköping, Sweden \\ arianit.kurti@tii.se \\ ${ }^{5}$ South East European University, Tetovo, Macedonia \\ b.raufi@seeu.edu.mk \\ ${ }^{6}$ Universitat Autònoma de Barcelona, Barcelona, Spain \\ david.salvador@e-campus.uab.cat
}

\begin{abstract}
Access to web content continues to be a challenge for the visually impaired, as the needs of such community are very diverse. The access is further hindered by the fact that designers continue to build websites noncompliant with Web Content Accessibility Guidelines (WCAG). To better understand the needs of the visually impaired community, three workshops were organized with various stakeholders coming from three different countries. The results from the workshops suggest that one-solution-fits-all model is inadequate without considering the levels of visual impairment when providing customized web experience. A set of requirements devised from the workshops guided the process of building a middleware prototype. Using eight adaptation techniques, the prototype provides the required user experience based on users level of visual impairment. Preliminary evaluation of the middleware suggests that several adaptation techniques perform better with non-WCAG compliant websites compared to those being compliant.
\end{abstract}

\section{Introduction}

The increased portability and wide adoption of diverse web content and mobile technologies have resulted in the fact that computers are not anymore perceived as distinct technological objects, but more as integrated tools to support our everyday activities [17]. The ubiquity of these environments creates the possibilities for people to communicate across multiple computational devices at the same time. These trends provided the opportunities for the evolvement of the web toward a fully-fledged software platform [18]. The main idea behind this view is the fact that people are actively engaged by contributing with digital content on the web through the use of different web and mobile applications and platforms across diverse devices [1].

All these developments result in new ways for people to create, share, manage everyday life, as well as communicate with their friends and family. The different 
levels of accessibility of these solutions directly affect their use by diverse user groups. Primarily this creates challenges for user groups with special needs. One such user group is the community of visually impaired people, which is usually marginalized. Some of their challenges include lack of proper access to the different web content that could facilitate their everyday activities.

Considering that this community is highly diverse, such as, in terms of levels of impairment, poses an additional challenge when addressing their needs. One way to better understand their needs was to consider different societies and levels of impairment when identifying the requirements. Moreover, considering various user interaction modalities and adaptation techniques, we believe helps in mitigating the problems when visually impaired users access web content.

Motivated by these challenges and research trends, in this paper we report our efforts on the web accessibility issues for the visually impaired community. The main effort is to understand the key requirements and provide initial solutions that could be utilized for providing access to web content for this marginalized group. To this end, we provide exploratory insights on the accessibility requirements identified through three workshops held in Macedonia and Sweden [6]. This was followed with the design activities and development of a middleware using contemporary web technologies in order to adapt a given website based on user needs. A preliminary user evaluation of the middleware prototype was conducted in Spain, which is reported in details in section 6 .

In the following sections of this paper we present our research approach followed with an overview of the accessibility requirements identified via realized workshops. Afterwards, we give details of initial design issues discovered and addressed in a prototype. At the end, we discuss initial findings from the prototype user evaluation and provide some challenges for future efforts.

\section{Background}

The idea of web accessibility is to make the web open to disabled people [8]. Contemporary web technologies also play a crucial role in this area $[9,23]$. However, web access suffers from interoperability and usability problems that make interaction of disabled users difficult $[8,23]$. Moreover, the need to improve the web browsing experience by adapting and personalizing the software to user preferences and device characteristics has become evident [8].

To ensure universal design and equal access to web content by all users, the World Wide Web Consortium (W3C) developed the Web Content Accessibility Guidelines (WCAG). These guidelines in many cases help mitigate problems that visually impaired users face when accessing web content. The current version of WCAG 2.0 was published on December 2008 as a W3C Recommendation and includes 12 guidelines organized in four principles [8]. However, WCAG 2.0 seems to not completely address the accessibility issues, where the low level guidelines (e.g., level A) are not fulfilling the needs of visually impaired users [14]. This research shows that the application of WCAG is often insufficient for visually impaired users, because of the overlooked factors, particularly in terms of efficiency and satisfaction. 
An interesting issue is that the implementation of WCAG 2.0 is still poor in most of governmental and news agencies websites [7]. Therefore the most used assistive technologies today are the screen readers which most of them are proprietary software in nature [3]. In this manner, most of the screen readers fail to notify in an efficient way that new content has appeared on the web site. This does not allow visually impaired users to fully experience and benefit from dynamic websites. A change in the overview of website design and a stronger inclusion of accessibility is needed given that visually impaired users still cannot fully benefit from the advantages of contemporary web technologies. Thus, there is a need for a new approach on "assisting" the assistive technologies that are open and that allow customizations in terms of personalized accessibility features.

With respect to these developments and as suggested by [10] there is a need for adaptation in enhancing web accessibility for visually impaired users. The advances of web technologies (such as HTML5 and web frameworks) offer a wide variety of adaptation possibilities that can be utilized to increase web accessibility. New web technologies offer a wide range of approaches and techniques for adaptation that were not possible when the WCAG 2.0 was developed. These developments bring new possibilities for increased accessibility of the web content. In this context, web adaptability encourages the development of web-based services that can be resilient to the diversity of uses of such services as well as target audiences $[10,11]$. These recent advances in the web technologies increase the possibilities for the adaptive approaches to better follow user preferences and get the most of the visual and navigation aspects by facilitating the interaction with the web content. Nevertheless, the web content adaptation becomes challenging especially when it needs to be applied to the specificities of the visually impaired users. In this manner we have identified two primary lines of adaptation when it comes to visually impaired users: content and modality adaptation approaches:

- Content adaptation approach involves displaying and transforming the web content in a more accessible way suitable to user preferences in a specific context $[4,11,22]$.

- Modality adaptation approach involves alternative content representation (often non-visual) that facilitate the content accessibility using voice narrators and other non-speech sounds $[4,5,11]$.

These adaptation approaches can be instantiated with a number of techniques especially by utilizing advances in the web technologies in order to increase accessibility of web content.

\section{Research Approach}

The rich technological landscape, in which we live in, enables us to use different devices to deploy, invoke, and represent web content that are related to our everyday context. These developments bring a palette of new opportunities to support an increased accessibility of the web content for the visually impaired users [20]. But in order to utilize and gain full benefit from these advances, a proper domain analysis of the visually impaired users' requirements is essential [13]. This type of analysis is 


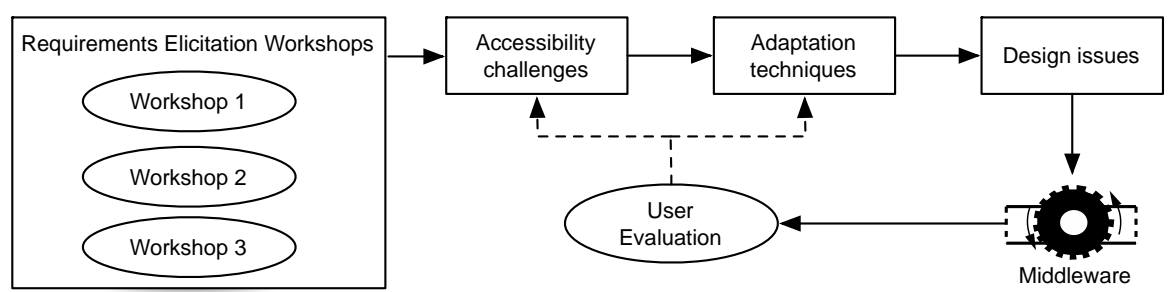

Fig. 1. Depiction of this study flow.

defined as a process that acquires, classifies and analyzes all requirements of domain stakeholders [15].

Having in mind that visually impaired community is rather a diverse group, we have utilized a need-driven approach based on active user participation in order to identify the needs in this domain. Another motivation for choosing a need-driven and user-oriented approach was the need to reduce the risk of over engineering as well as avoiding defective requirements [2]. Motivated from this and trying to get the best grasp of the domain analysis, we organized three workshops with different stakeholders from various ethnic, cultural, professional and socio-demographic backgrounds. Workshops have been organized in Macedonia (one) and Sweden (two).

The aim of the first workshop held in Macedonia was to enable an in depth understanding of the needs and requirements of the visually impaired community. Whereas, the aim of the second and third workshop held in Sweden was to validate the identified requirements in the first workshop and bring the diverse research expertise on the domain. These three workshops have been followed with a discussion activity with Optic and Optometry specialists in Spain. The purpose of this activity was to understand how different optical deficiencies could be compensated by utilizing the advances of the web technologies. The overall flow of the research activities conducted in this study is depicted in Fig. 1.

\subsection{Workshop Settings and Stakeholders}

The first workshop was held at South East European University in Tetovo, Macedonia and gathered various participants starting from research community, visually impaired people, and non-governmental organizations (NGO's) working especially with visually impaired people. The workshop hosted a total of 21 participants (12researchers and students from the web and mobile technologies and Human-Computer Interaction (HCI) fields; 4-representatives of educational establishments; 2-NGO representatives; and 3-visually impaired students).

The second workshop was held in Kalmar at Linnaeus University, Sweden. The added value of this workshop was the inclusion of additional stakeholders from the fields such as eHealth and Optometry. In total it gathered 11 participants (3-eHealth; 1-optometrist researcher; 1-visually impaired; and 6-researchers from various fields of web and mobile technologies and $\mathrm{HCI}$ ). 


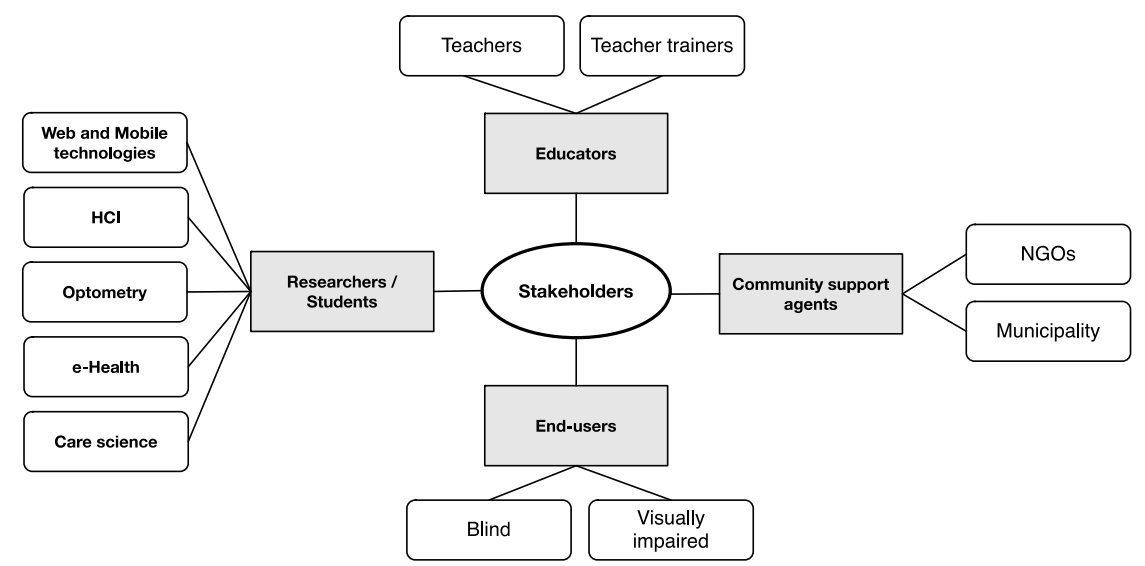

Fig. 2. Ecosystem view of the stakeholders [6].

The third workshop took place at Blekinge Institute of Technology in Karlskrona, Sweden. This workshop included additional stakeholders coming from the fields of Applied Health Technologies, Interaction Design and Caring Sciences. In total it gathered eight participants (3-health technologies; 1-Informatics; and 4-from various fields of Computer Science).

These three workshops helped us identify various accessibility challenges and adaptation techniques, which were later implemented in a middleware prototype that utilized a number of adaptation techniques to increase the web content accessibility. Furthermore, in a direct discussion with a specialist from Terrassa School of Optics and Optometry of the Universitat Politècnica de Catalunya we have further specified the exact adaptation techniques that would be used to determine key functional requirements of the middleware. A follow up user evaluation of the middleware was then conducted with visually impaired users from the same institution.

In order to gain a better insight of different stakeholders involved in the research activities, an ecosystem scheme of the stakeholders is depicted in Fig. 2. The ecosystem view became a confluence between educators, researchers, community support agents and most importantly, the end users, i.e., the visually impaired. This research approach enabled us to build up knowledge about different accessibility challenges, adaptation approaches and techniques when dealing with visually impaired user needs.

\section{Web Accessibility Challenges}

The discussion with stakeholders during the three workshops provided a good empirical base to understand the main challenges that keeps the visually impaired as a marginalized community (especially in Macedonia and the surrounding region). List of all challenges identified in the workshops are detailed in [6], while in this paper we mainly emphasize on the web content accessibility challenges for visually impaired people. 
Table 2. Contextual factors [6].

\begin{tabular}{lll}
\hline \multicolumn{1}{c}{ Factors } & \multicolumn{1}{c}{ Description } & \multicolumn{1}{c}{ Testing activities } \\
\hline Day/time of use & $\begin{array}{l}\text { The impact of natural light and time of day in } \\
\text { user's activities }\end{array}$ & Functionality testing \\
Location & $\begin{array}{l}\text { User activity influenced by his location } \\
\text { (indoor, outdoor, in a car, train, etc.) }\end{array}$ & Mobility testing \\
Device/Platform & $\begin{array}{l}\text { The impact of device type, size and platform } \\
\text { in user's activities }\end{array}$ & $\begin{array}{l}\text { Interoperability } \\
\text { and/or compatibility } \\
\text { Ope level of user disability }\end{array}$ \\
User profile & The lometric testing/ \\
Accessibility & $\begin{array}{l}\text { An overarching factor that ensures } \\
\text { achievement of all previous factors }\end{array}$ & $\begin{array}{l}\text { Heuristics/ } \\
\text { Usability/field testing }\end{array}$ \\
\hline
\end{tabular}

The analysis of the data gathered during the workshops, helped us identify two important aspects that inform the process of interface requirements for the visually impaired community. The first factor is related to contextual factors and pertains to the fact that web applications have increased in importance due to the relevance of the user context (i.e., profile, activities, and location). Table 2 highlights different contextual factors motivated particularly for (a) the importance due to the user context that plays nowadays, (b) the end-user satisfaction, (c) and the significant impact on the quality of the overall user experience, particularly visually impaired people. For instance, a particular website could be accessible on Windows, but not on OS X or diverse mobile platforms, because of a lack of sophisticated screen reader. Or following the WCAG guidelines does not guarantee that all visually impaired people will gain the satisfactory level access to digital information. A website could pass all WCAG validations, but still be unusable due to a lack of screen readers available for a particular language.

To overcome situations when contextual factors play negative role in achieving satisfactory user experience, in our previous studies we have used non-speech sounds to deliver content to visually impaired users. In the process of auralizing content and deliver it in a non-visual form, we have successfully developed and evaluated audemes as a novel non-speech sounds to deliver educational content in experiments conducted with K12 students in a visually impaired school in U.S. [5]. Audemes are brief non-speech sounds created of music and sound effect sound snippets referring to natural, artificial or abstract sounds, even popular music.

An interesting insight from one of the workshops revealed the second factor that highlights the necessity to "teach" visually impaired how to make the best use of their remained sight. An optometrist present at the workshop argued that many visually impaired people could pass the legally blind threshold by learning techniques of using peripheral vision [12]. Designing interfaces for visually impaired users familiar with such techniques would require understanding their specific needs, rather than treating them as homogenous group. 


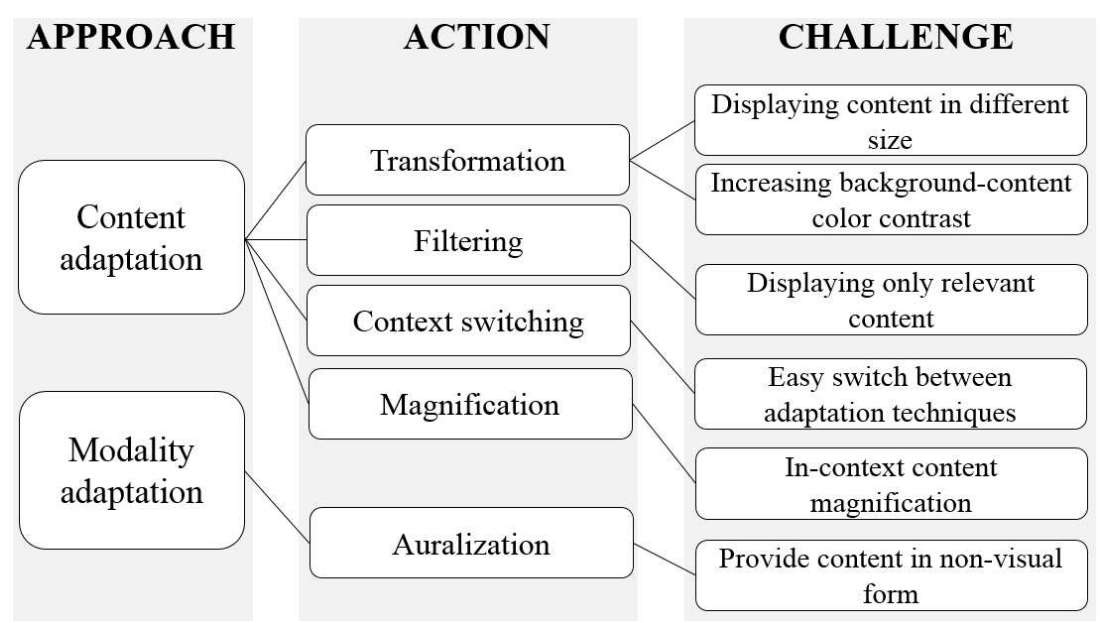

Fig 3. Accessibility challenges, actions and adaptation approaches for BVI users.

While various web adaptation techniques could be used to deliver usable content to visually impaired users, the one-size-fits-all model, however, does not provide satisfactory solution. Hence, a specific user requirement should be gathered to apply the specific adaptation technique suitable for the user. Based on user's level of impairment, a particular solution should be suggested. To achieve such goal, as a result of the workshops we have identified specific challenges different users face when accessing web content. Fig. 3 lists these challenges along with the actions and approaches anticipated to address them.

All these challenges identified from the workshops had as a common denominator, the need to access diverse web content in a more accessible way, and beyond the WCAG guidelines. This inspired the idea of a middleware that would enable applying adaptation techniques of existing web content primarily possible due to the advances in the web technologies.

In order to identify the best adaptation techniques to be implemented into the middleware, we have discussed our ideas with an optician specialist. The result of this discussion indicated that some visually impaired users feel more comfortable with a different contrast rather than the usual black over white. This inspired the idea of color transformation as part of our middleware solution. Furthermore, it is desirable to offer the flexibility of increased text and other content on the web site, but this should not be on the expenses of losing the navigational context of the page. For that reason this inspired us to implement an amplifying text lens that enables the visually impaired user to read the text with an increased size, but without losing the context of the entire web page. All this served as a solid background to initiate our prototyping efforts for the design and implementation of the middleware solution.

\section{Design Issues and Implementation Details}

The design activities and implementation of the prototype solution was highly motivated by contemporary web technologies. Both, the design and the requirements 
Table 3. Requirements and related techniques to address identified challenges.

\begin{tabular}{|c|c|c|c|c|}
\hline Approach & Action & Technique & Requirement & Rationale \\
\hline \multirow{6}{*}{ 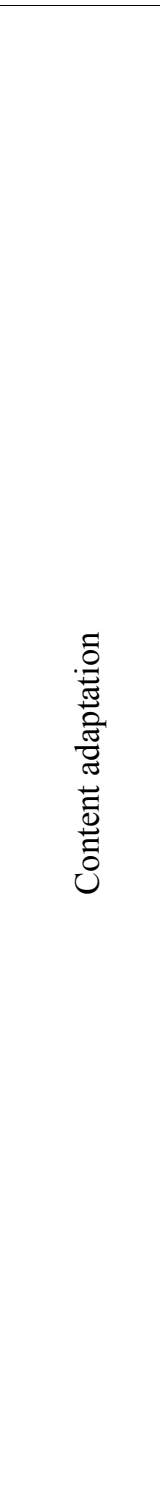 } & \multirow{3}{*}{ 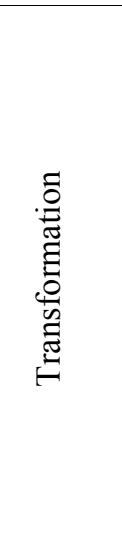 } & $\begin{array}{l}\text { Image } \\
\text { transformation } \\
\text { / resizing }\end{array}$ & $\begin{array}{l}\text { System must display } \\
\text { the images of the } \\
\text { requested page into a } \\
\text { more accessible way }\end{array}$ & $\begin{array}{l}\text { To enable the } \\
\text { user to recognize } \\
\text { an image and it } \\
\text { in the given } \\
\text { context }\end{array}$ \\
\hline & & $\begin{array}{l}\text { Text } \\
\text { transformation }\end{array}$ & $\begin{array}{l}\text { System must have the } \\
\text { option of transforming } \\
\text { the text in a more } \\
\text { accessible way }\end{array}$ & $\begin{array}{l}\text { Enable the user } \\
\text { read the content } \\
\text { easily }\end{array}$ \\
\hline & & $\begin{array}{l}\text { Color } \\
\text { transformation }\end{array}$ & $\begin{array}{l}\text { System must have the } \\
\text { option of changing the } \\
\text { contrast of chosen } \\
\text { website }\end{array}$ & $\begin{array}{l}\text { Enable user } \\
\text { differentiate } \\
\text { between text and } \\
\text { background }\end{array}$ \\
\hline & : & Image filtering & $\begin{array}{l}\text { System must have the } \\
\text { option of showing in } \\
\text { the adapted page only } \\
\text { the main content of the } \\
\text { requested page }\end{array}$ & $\begin{array}{l}\text { Enable the user } \\
\text { differentiate } \\
\text { between relevant } \\
\text { and irrelevant } \\
\text { images in the } \\
\text { website context } \\
\text { Enable the user } \\
\text { identify the main } \\
\text { content of the } \\
\text { website }\end{array}$ \\
\hline & 茬 & $\begin{array}{l}\text { Switching } \\
\text { control }\end{array}$ & $\begin{array}{l}\text { System must have a } \\
\text { control to allow } \\
\text { dynamic changes of } \\
\text { the adaptation features }\end{array}$ & $\begin{array}{l}\text { Enable the user } \\
\text { to switch } \\
\text { between } \\
\text { adaptation } \\
\text { modes } \\
\text { depending on } \\
\text { their need. }\end{array}$ \\
\hline & 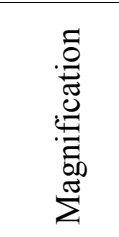 & $\begin{array}{l}\text { Amplifying } \\
\text { lens }\end{array}$ & $\begin{array}{l}\text { System must have a } \\
\text { lens to amplify the text } \\
\text { and images of the } \\
\text { website }\end{array}$ & $\begin{array}{l}\text { Enable the user } \\
\text { better reading of } \\
\text { desired content }\end{array}$ \\
\hline 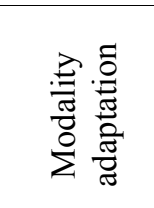 & . & Voice narrator & $\begin{array}{l}\text { System must have a } \\
\text { voice narrator (text-to- } \\
\text { speech) to navigate } \\
\text { and read the content in } \\
\text { an auditory format }\end{array}$ & $\begin{array}{l}\text { Enable the user } \\
\text { consume the } \\
\text { content in an } \\
\text { auditory form }\end{array}$ \\
\hline
\end{tabular}




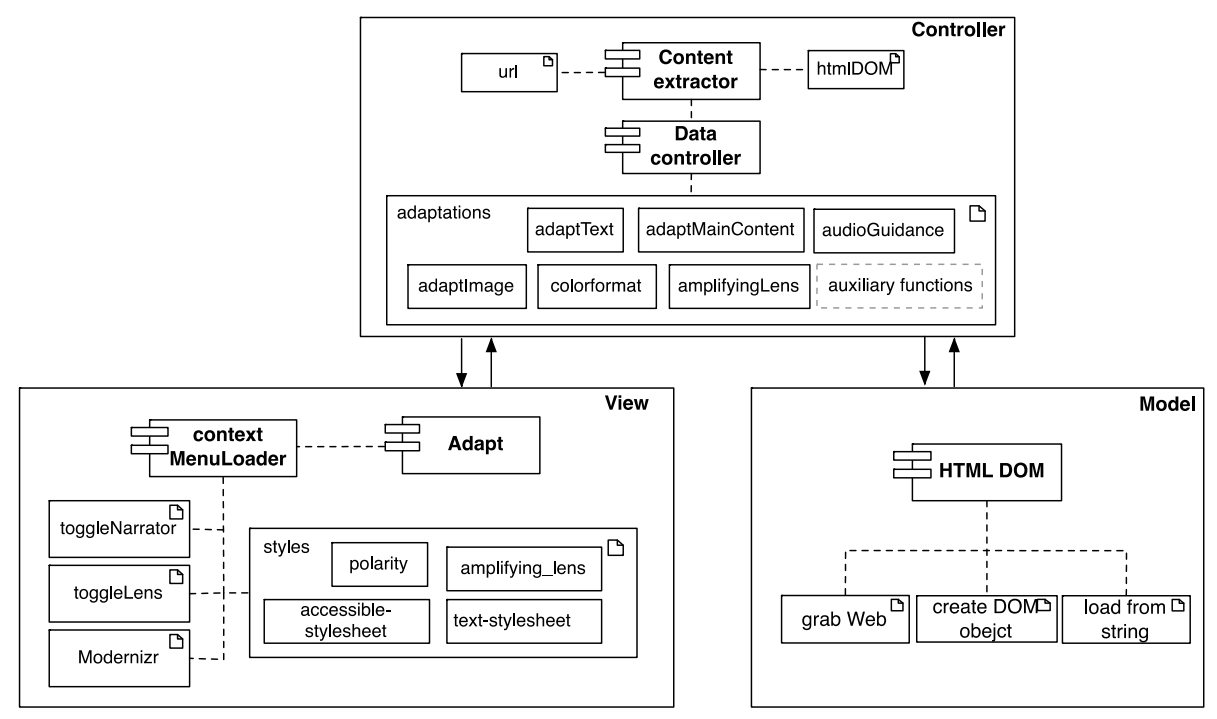

Fig. 4. Architectural overview of the solution based on MVC.

(listed in Table 3) of our prototype design, were motivated from: the adaptation approaches identified in section two, three workshops, and individual meetings with an Optics and Optometry specialist. Considering these requirements, we have developed a prototype solution that adapts a given website based on user's preferences and their disability.

In order to provide a fully accessible web content, our solution transforms any available web site by making it WCAG 2.0 compliant. Moreover, one of our goals with our solution was to reach the following:

1. To offer different types of visual adaptations for various levels of impairment.

2. To provide the best personalized user experience for the existing web content (such as governmental portals, news agencies and other).

Table 3 lists the requirements identified, which essentially address challenges listed in Fig. 3. In addition, this table lists the technique and rationale for each requirement. Given these requirements and the related technique needed to be implemented into our prototype, the architectural choice was motivated following the software architectural pattern, the Model-View-Controller (MVC) that lately is being highly used in modern web technologies. This architectural pattern is composed of three parts: the Model - corresponds to the data, the View - is the representation of the data, and the Controller - manages the data.

The reason of utilizing this pattern is that it allows decoupling the visual representation of the data and its management. As such, it provides solutions to flexibly address the requirements identified in Table 3, and in the future extend our solution with new features in a more flexible manner. The solution prototype is implemented by utilizing contemporary web technologies in terms of HTML5, CSS, JavaScript and PHP as well as external libraries including: HTML DOM, Modernizr, jQuery, Web Speech API, Lens effect, TextScrolling, and contextJS (source code: https://github.com/davidsalvador/degree-project). 


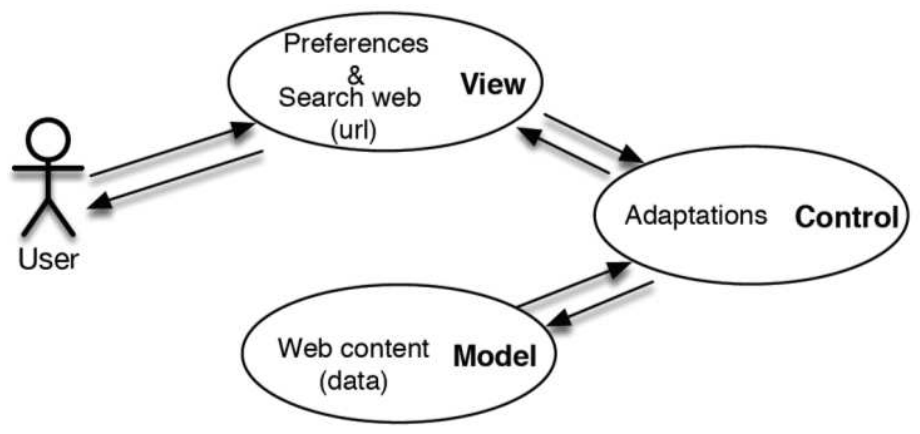

Fig. 5. Use case diagram.

All adaptation techniques identified in Table 3 are carefully implemented into our solution. Fig. 4, presents the architectural overview of our prototype solution. The "Controller" and the "View" play a central role in our solution. The "Controller" usually manipulates the "Model" elements and updates the "View". The "Model" of the solution is formed by all HTML elements. The "Content extractor" component in the "Controller" uses a third-party library (HTML DOM), which belongs to the "Model" part. The HTML DOM parser makes it possible to manipulate the HTML elements of a certain web page and its content. The "Data controller" component manages the data extracted from "Content extractor" and afterwards applies different adaptations (see details in Fig. 4). The "View" is responsible for representations. It gets the adaptations and presents them to the user. Usually the "Controller" applies the static changes, whereas the "View" allows the user to change the options and automatically reload the page to display the new content by using the "contextMenuLoader" component. In general, the "View" allows to dynamically change and adapt the web content to different styles and features without reloading the page.

To better understand our solution prototype, a usage scenario is presented in Fig. 5. The typical steps depicted in the use case diagram are:

1. The user enters the URL of the page to browse into the prototype along with the types of adaptations selected (preferences).

2. The solution requests the original website (gets web content and data) and applies the adaptations requested.

3. Finally the adapted page is presented based on the chosen user preferences.

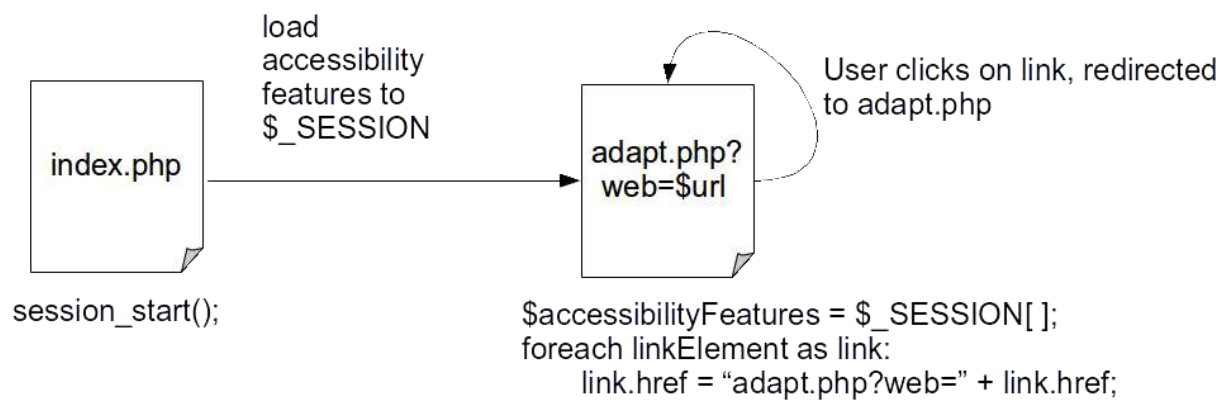

Fig. 6. Persistent adaptations. 


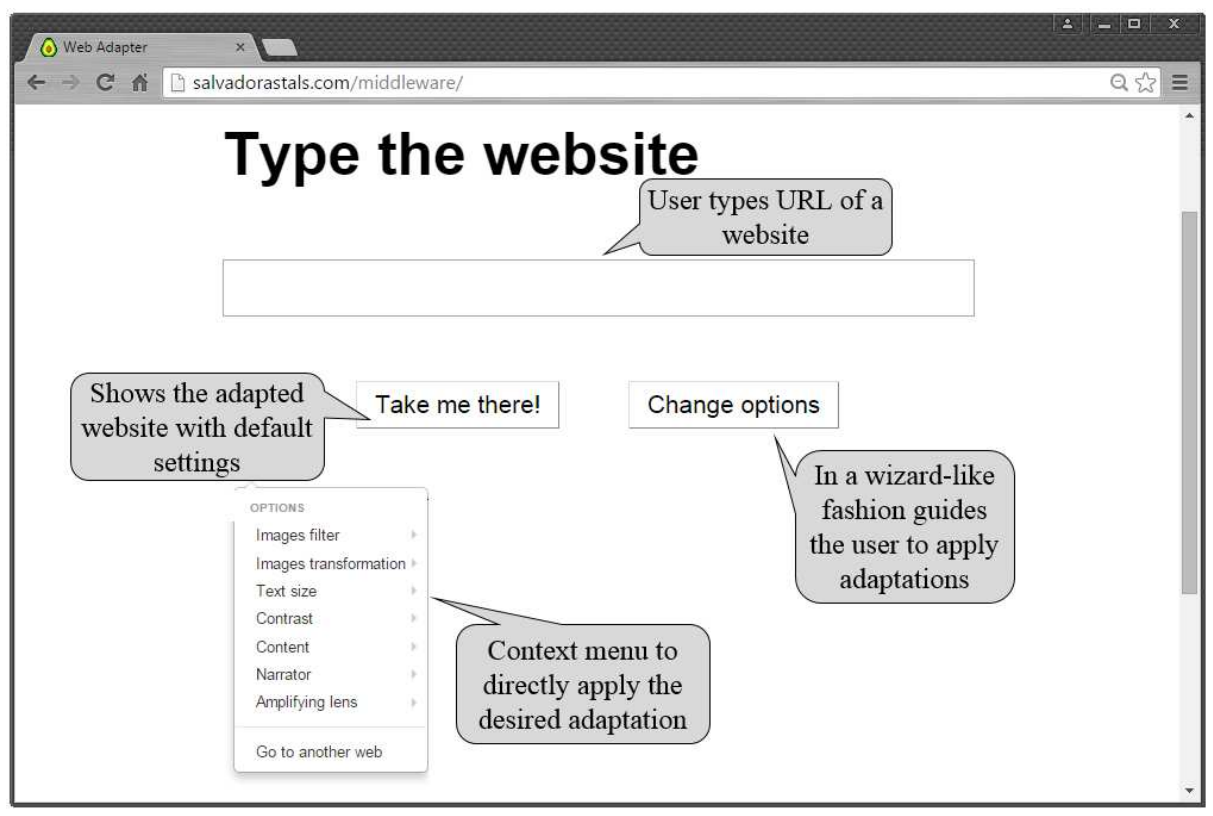

Fig. 7. Prototype homepage and contextual menu.

In order to conserve the adaptations chosen by the user, persistent adaptation is applied, enabling that in every subsequent browsing instance, the requested page will be adapted based on the same chosen preferences as the last browsing experience. Before the user searches the web, session cookie is initiated where the features chosen by the user will be stored. The "href" attribute of every anchor HTML element is modified by appending "adapt?web" string to the URL. Using this, all links will refer the "adapt" page where the adapted web content is received as a GET parameter. In this way, every petition that the "adapt" page receives, the session features (variables) are read from the cookie and the adaptations are made available based on the preferences chosen by the user (see Fig. 6). In other words, for each URL submission the adapt.php is called. We must clarify that at this stage, the two-way communication of form handling (e.g., searching) has not been implemented.

In order to rationalize the design and implementation, Fig. 7 presents the screen shot of the protoype solution. The simple and user-friendly interface shows a textbox for typing the requested site and two buttons. The button "Take me there!" takes the user to the desired website with default adaptations. The button "Change options" offers the user the ability to alter the default settings in a wizard-like fashion by guiding them through each adaptation. If users right-click anywhere on the page, a context menu is shown giving them the option to directly apply a desired adaptation, e.g., change the text size.

To better illustrate the effects of adaptation of a given website, in Fig. 8 and 9 we show the original and adapted version of the University of Barcelona website with default adaptation settings. The prototype solution removes irrelevant images, such as logos, and leaves only images that refer to content. Fig. 9 shows that the menu links are transformed into a form that more clearly indicates them being clickable links. 
When users hover with a mouse over a given paragraph, such as the one highlighted in yellow in Fig. 9, the content will show and slide left-to-right with a bigger font on a small window below the paragraph. As the content slides, it is also read at loud using a text-to-speech voice narration. The middleware prototype can be accessed at: http://salvadorastals.com/middleware/

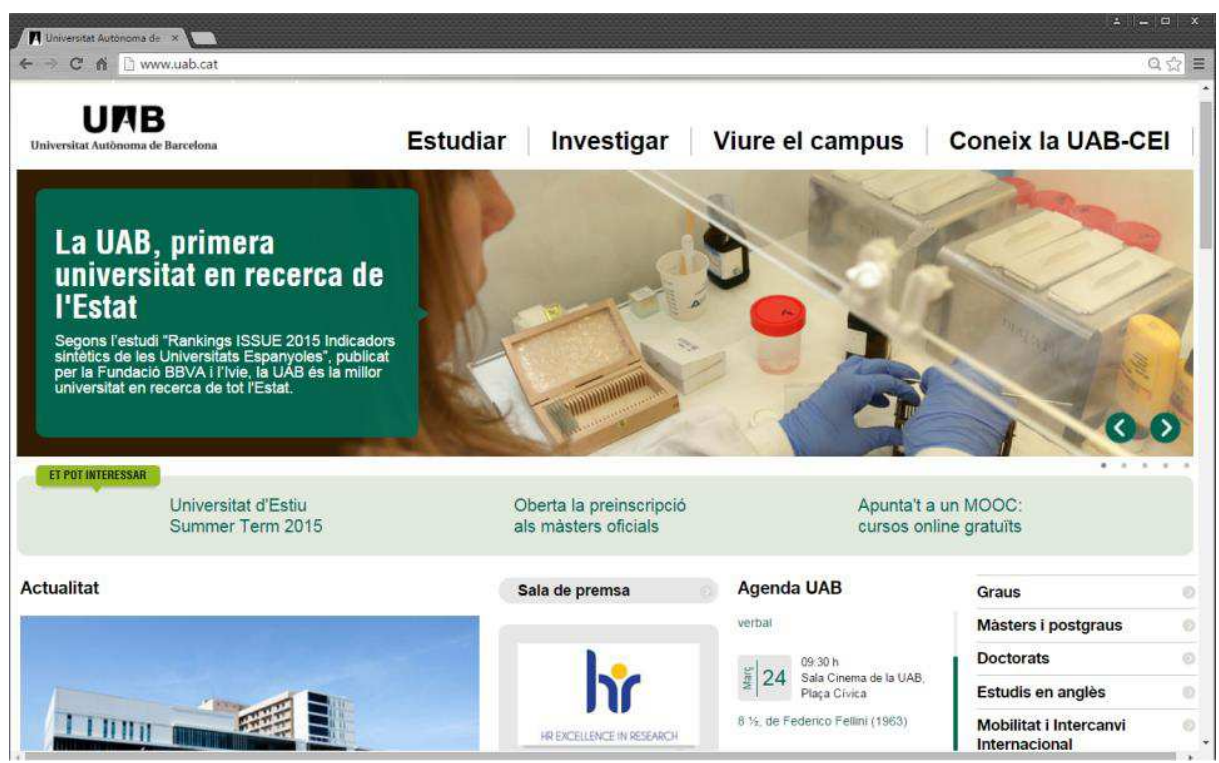

Fig. 8. The University of Barcelona website without adaptation.

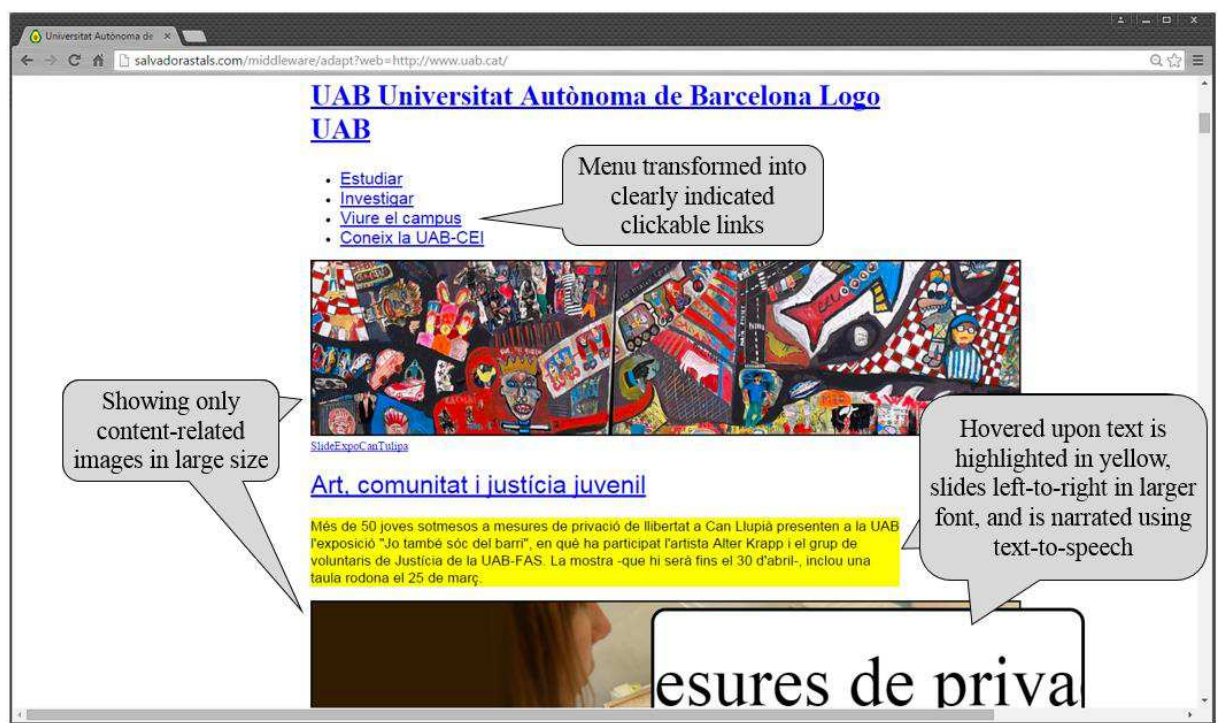

Fig. 9. The University of Barcelona website with default adaptations applied. 


\section{Prototype Evaluation}

The user evaluation of the middleware was conducted involving four visually impaired users from the Terrassa School of Optics and Optometry of Universitat Politecnica de Catalunya. The evaluation process consisted of three phases. Initially, the participants were given time to familiarize with the middleware and discover its features. Afterwards, participants were asked to find a particular information from a given website. To accomplish this task, each participant chose the middleware settings of their choice. Finally, after participants completed the tasks, they were interviewed to record their feedback about their experience with the middleware.

\subsection{Participants}

Individual characteristics of each participant is given in Table 4 below. Participants were between 28 and 70 with various types of disability, years of low vision and internet usage per day. One common factor among all participants was that they used the Window Eyes screen reader.

\subsection{Procedure}

Each participant was sent an email with test instructions and two links. The first link corresponded to the middleware interface, while the second link contained the evaluation survey. Two participants tested the website of the Universitat Autonoma de Barcelona (http://uab.cat), which was WCAG 2.0 non-compliant at the time of testing. Two other participants tested the ONCE website (the Spanish National Blind Association, http://once.es), which was WCAG 2.0 level AA compliant at the time of testing. The WCAG compliance was checked using the achecker online tool (http://achecker.ca).

The following steps were involved:

- Step 1: The participant familiarizes with using the middleware interface, and playing with the features to find the best fit for their needs. (At this point, participants are not yet exposed to the two testing websites.)

- Step 2: The participant is randomly assigned to either the WCAG compliant or non-compliant website in which he is instructed to find a given information.

Table 4. Participant demographics.

\begin{tabular}{lcclcl}
\hline PID & Age & $\begin{array}{c}\text { Hours of Internet } \\
\text { per day }\end{array}$ & $\begin{array}{c}\text { Assistive } \\
\text { software }\end{array}$ & $\begin{array}{c}\text { Years of } \\
\text { low vision }\end{array}$ & Pathology \\
\hline A & 45 & 4 & Window Eyes & 12 & Magna myopia \\
$\mathrm{B}$ & 65 & 2 & Window Eyes & 2 & $\begin{array}{l}\text { Glaucoma } \\
\text { Age Related Macular }\end{array}$ \\
$\mathrm{C}$ & 70 & 1 & Window Eyes & 5 & $\begin{array}{l}\text { Degeneration } \\
\text { (ARMD) }\end{array}$ \\
$\mathrm{D}$ & 28 & 5 & Window Eyes & 28 & Retinitis pigmentosa \\
\hline
\end{tabular}


- Step 3: After the participant accomplishes the task, he is instructed to answer the survey, which consisted of three parts: (i) questions gathering information about participant's demographics including their experience with technology and the type and level of visual impairment; (ii) questions highlighting whether the participant was able to find the information required from the given website, indicating Yes, No or Partially Found; and (iii) using a combination of Likert scale and openended questions participants were required to evaluate the usability of the middleware interface.

\subsection{Results and Discussion}

Participants were successful in finding the required information from the randomly assigned website. Only one out of four participants was not able to find the information required, to whom a WCAG 2.0 non-compliant website was assigned.

Two adaptation techniques, text transformation and amplifying lens, were rated with maximum score (6.0) by all participants whether using a WCAG 2.0 compliant or non-compliant website. This result proves that these two techniques were well accepted by participants regardless of the level of WCAG compliance the website had.

A technique that the WCAG compliance of the website had the most effect was Image filtering, which was rated very differently depending on whether participants used a non- or compliant website. Participants using non-compliant website rated this technique with maximum score (6.0), while participants using a compliant website rated it with a minimal score (2.0). We believe this result indicates that the website does not need to be WCAG 2.0 compliant for an adaptation technique to be useful.

Table 5. Prototype evaluation results.

\begin{tabular}{|c|c|c|}
\hline 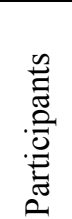 & $\begin{array}{l}\text { Middleware feature / } \\
\text { Adaptation technique }\end{array}$ & 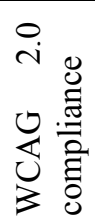 \\
\hline
\end{tabular}

\begin{tabular}{|c|c|c|c|c|c|}
\hline 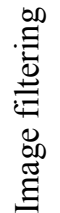 & 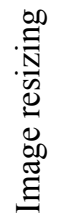 & 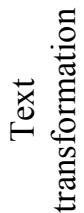 & 节 & 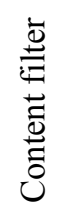 & 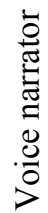 \\
\hline
\end{tabular}

\begin{tabular}{ccccccccc}
\hline A & 2 & 2 & 6 & 3 & 2 & 2 & 6 & Yes \\
B & 2 & 2 & 6 & 1 & 5 & 6 & 6 & Yes \\
C & 6 & 3 & 6 & 3 & 6 & 3 & 6 & No \\
D & 6 & 3 & 6 & 2 & 6 & 2 & 6 & No \\
\hline Mean & 4 & 2.5 & 6 & 2.25 & 4.75 & 3.25 & 6 & - \\
\hline
\end{tabular}


Developing an accessible website typically requires extra amount of work, which due to financial aspects, forces decision makers to often opt against the implementation of WCAG. Hence, this result suggests that the middleware eliminates the necessity for a website to comply with WCAG.

The content filter technique received high rating from three participants, while one participant using a WCAG compliant website gave a poor rating. The image resizing and contrast transformation techniques received below the average rating. Further studies need to be conducted in order to identify reasons that make these techniques less successful. The only technique addressing a non-visual (auditory) requirement was the voice narrator. This technique was rated average by all but one user, who gave it a maximum score using a WCAG compliant website. Summarized quantitative values of the results are given in Table 5.

Few participants gave negative comments concerning aspects of the middleware homepage. One participant requested that the font size of the contextual menu be higher, while another participant stated that it would be easier to use the middleware as a search engine, rather than requiring to input the entire URL into the box.

\section{Conclusion and Future Work}

In this paper we presented requirements gathered from three workshops held with different stakeholders to identify the needs of visually impaired users. The novelty of this study was the identification of two important factors relevant when addressing the needs of visually impaired people. The first factor identified was the context of use, which influences the accessibility of digital content for the visually impaired users. The second factor was the need to evaluate user's level of visual impairment before applying any adaptation technique on the existing web content.

The outcome of the realized workshops was the generation of requirements that guided the development of a middleware prototype that made websites usable by adapting them based on user's visual impairment level. The user evaluation of the middleware indicated that several adaptation techniques perform better with non WCAG compliant websites than with those being compliant. Overall, adaptation techniques were useful to our participants.

Although this study used just four participants, it is still important because of two reasons. First, it gives an indication that requirements gathered and the middleware built are an approach in the right direction. The user testing provides some initial insights both regarding the middleware prototype as well as validating the approach in gathering requirements using workshops. Second, it is typical that studies involving people with disabilities are conducted only with several participants. Limitations in terms of mobility and skill qualification of these people are usually the underlying reasons [19]. To an extent, this study is an effort in addressing this issue by giving greater access to information to visually impaired users.

In line with such efforts, we are currently investigating Massive Open Online Course (MOOC) as a means to provide quality education to visually impaired people [16]. Future efforts need to gather requirements for building accessible MOOCs and the skills required for the users to have in order to be able to access web content. 
Moreover, building and evaluating how different adaptation techniques contribute toward achieving greater web content accessibility will present a step in the direction to increase the number of visually impaired community participating in online education.

In the future, in order to increase content accessibility, new adaptation approaches could be investigated by leveraging open data and standards together with emerging web technologies. In addition, this would enable architectural solutions that are capable to deal with dynamic requirements and heterogonous environments in web and mobile technologies [21]. These two lines of action represent important future research challenges, as we believe that they are key aspects to influence accessibility needs and emerging technologies in general, and in particular of the visually impaired community.

Acknowledgments. We thank all participants from Kosova, Macedonia and Sweden that attended our workshops. We thank the eHealth Institute in Kalmar and Blekinge Institute of Technology in Karlskrona, for hosting our workshops. Furthermore, we thank the professor of UPC - FOOT, Eulalia Sánchez, for her scientific, optical and optometry approach and counseling during the assessment study. Finally, we thank the Swedish Foundation for International Cooperation in Research and Higher Education for supporting this research.

\section{References}

1. Berners-Lee, T, Long live the Web: a call for continued open standards and neutrality, Scientific American, vol. 303, no 4 (Dec) 2010, pp. 56-61.

2. Braude, E. J., and Bernstein, M. E., Software Engineering: Modern Approaches, 2nd Edition. John Wiley and sons. NJ, 2011.

3. Brown, A., Jay, C., Chen, A. Q. and Harper, S., The uptake of web 2.0 technologies, and its impact on visually disabled users, Univers. Access Inf. Soc., vol. 11, no. 2, pp. 185-199, Jun. 2012.

4. Brusilovsky, P. (2001). Adaptive Hypermedia. User Modeling and User-Adapted Interaction. $11,87-110$.

5. Ferati, M., Pfaff, M., Mannheimer, S., and Bolchini, D., Audemes at work: Investigating features of non-speech sounds to maximize content recognition, Int. J. Human-Computer Studies (IJHCS), 70 (12), 2012, 936-966.

6. Ferati, M., Raufi, B., Kurti, A., Vogel, B., Accessibility Requirements for Blind and Visually Impaired in a Regional Context: An Exploratory Study, In Proceedings of the 2nd IEEE International Workshop on Usability and Accessibility focused Requirements Engineering (UsARE'14), August 25-29, Karlskrona, Sweden, 13-16

7. Hanson, V. L. and Richards, J. T., Progress on website accessibility? ACM Trans. Web, vol. 7, no. 1, pp. 2:1-2:30, Mar. 2013.

8. Harper, S., Yesilada, Y., (Eds.) Web Accessibility: A Foundation for Research. In Human Computer Interaction Series. Springer-Verlag. 2008.

9. Johari, K. and Kaur, A. (2012). Measuring web accessibility for persons with disabilities. In Computational Intelligence and Communication Networks (CICN), 2012 Fourth International Conference on (pp. 963-967). IEEE.

10. Kelly, B., Nevile, L., Sloan, D., Fanou, S., Ellison, R. and Herrod, L. (2009) From Web Accessibility to Web Adaptability. Disability and Rehability: Assistive Technology, 4 (4). 
11. Knutov, E., De Bra, P.M.E. \& Pechenizkiy, M. (2009). AH 12 years later: a comprehensive survey of adaptive hypermedia methods and techniques. New Review of Hypermedia and Multimedia. 15(1), 5-38.

12. Lewis, P., Rosén, R., Unsbo, P., Gustafsson, J., Resolution of static and dynamic stimuli in the peripheral visual field. In J. Vision Research. 51. 1829-1834. 2011.

13. Ludi, S., Canter, A., Ellis, L., Shrestha, A., Requirements gathering for assistive technology that includes low vision and sighted users. In Usability and Accessibility Focused Requirements Engineering (UsARE), 2012 First International Workshop on (pp. 25-31). 2012.

14. Power, C., Freire, A. P., Petrie, H., and Swallow, D., Guidelines are Only Half of the Story: Accessibility Problems Encountered by Blind Users on the Web, CHI'12, May 5-10, p.1-10, 2012, Austin, Texas, USA.

15. Qiu, F. L., and Yin, L., Research on Domain Requirement Analysis Method Used Ontology. In Computational Intelligence and Design, 2009. ISCID'09. Second International Symposium on (Vol. 1, pp. 299-301). 2009.

16. Rizzardini, R. H., Chang, V., Gütl, C., and H. Amado-Salvatierra, An Open Online Course with Accessibility Features. In . Jan Herrington et al. (Eds.), Proceedings of World Conference on Educational Multimedia, Hypermedia and Telecommunications 2013 (pp. 635-643). Chesapeake, VA: AACE.

17. Sheth, A., Computing for Human Experience: Semantics-Empowered Sensors, Services, and Social Computing on the Ubiquitous Web. IEEE Internet Computing, vol. 14, no. 1, pp. 88-91, January/February, 2010.

18. Smith, K., How Digital Outcasts Can Pilot the Future of Health Care. In World Future Review. vol. 5 no. 2 127-134. 2013.

19. Stevens, R. D. (1996). Principles for the design of auditory interfaces to present complex information to blind people. D.Phil. Thesis, Department of Computer Science, University of York.

20. Terven, J. R., Salas, J., and Raducanu, B., New Opportunities for Computer Vision-Based Assistive Technology Systems for the Visually Impaired, Computer, vol. 47, no. 4, pp. 52$58,2014$.

21. Vogel, B., Kurti, A., Mikkonen, T., Milrad, M. (2014). Towards an Open Architecture Model for Web and Mobile Software: Characteristics and Validity Properties. In proceedings of the 38th Annual International Computers, Software \& Applications Conference (COMPSAC'2014), Västerås, Sweden, July 21-25, 2014. IEEE.

22. Watanabe, W. M., Candido,A., Amâncio, M. A., De Oliveira, M., Pardo, T. A. S., Fortes, R. P. M., Aluísio, S. M., Adapting Web content for low-literacy readers by using lexical elaboration and named entities labeling New Review of Hypermedia and Multimedia Vol. 16, Iss. 3, 2010.

23. Zhou, X. C. and Xia, X., Design and Research for Mobile Web Learning Platform Accessibility. Artificial Intelligence and Education (ICAIE), 2010 International Conference on. 2010. IEEE. 